\title{
A Novel QTL for Root-Knot Nematode Resistance is Identified from a South African Sweet Sorghum Line
}

\author{
Karen R. Harris-Shultz, ${ }^{1, \dagger}$ Richard F. Davis, ${ }^{2}$ Jason Wallace, ${ }^{3}$ Joseph E. Knoll, ${ }^{1}$ and Hongliang Wang 4 \\ ${ }^{1}$ United States Department of Agriculture-Agricultural Research Service (USDA-ARS), Crop Genetics and Breeding Research Unit, \\ 115 Coastal Way, Tifton, GA 31793 \\ 2 USDA-ARS, Crop Protection and Management Research Unit, 2747 Davis Road, BLDG 1, Tifton, GA 31794 \\ ${ }^{3}$ Department of Crop \& Soil Sciences, University of Georgia, 111 Riverbend Road, Athens 30602 \\ ${ }^{4}$ USDA-ARS, Hard Winter Wheat Genetics Research, 4007 Throckmorton Hall, Manhattan, KS 66506 \\ Accepted for publication 20 February 2019.
}

\begin{abstract}
Southern root-knot nematodes, Meloidogyne incognita, feed on the underground portions of hundreds of plant species and affect nutrient partitioning and water uptake of the host plants. Sorghum (Sorghum bicolor) is often not significantly damaged by southern root-knot nematodes (RKN) but some sorghum genotypes support greater population densities of RKN than other genotypes. These higher nematode populations increase the risk of damage to subsequently planted susceptible crops. A previous study identified a major quantitative trait locus (QTL) for RKN resistance on sorghum chromosome (chr.) 3. To maintain long-term resistance, multiple resistance genes should be pyramided in a cultivar. In this study, we identified a new source of RKN
\end{abstract}

ABSTRACT

Southern root-knot nematodes (RKN) feed on a wide host range of plants, have worldwide distribution in mild temperate areas to tropical and subtropical regions, and reproduce by parthenogenesis (Donkers-Venne et al. 2000; Favery et al. 2016). In terms of crop damage, RKN are considered the most economically important plant-parasitic nematodes (Danchin et al. 2013), feeding on the roots, bulbs, and tubers of thousands of plant species. Economically important crops, including cotton (Gossypium hirsutum L.), tobacco (Nicotiana tabacum L.), food legumes, vegetables, spices, and coffee (Coffea spp.), can be damaged severely by RKN (Choi et al. 2017; Ramana and Eapen 1995). Damage to the underground portions of the plants reduces water and nutrient uptake, thus reducing plant vigor and yield.

To control RKN, farmers frequently use soil fumigants or other nematicides, crop rotation, and resistant cultivars. Some of the commonly used nematicides such as 1,3 dichloropropene (Telone II, Curfew) and fenamiphos (Nemacur), which were used as alternatives to methyl bromide, have been banned by the European Union and the U.S. Environmental Protection Agency, respectively, due to high toxicity to animals and the environment (Crow 2005; Danchin et al. 2013). The most sustainable control methods with the least potential for human harm and environmental damage are crop rotation and the use of RKN-resistant cultivars. Unfortunately, the

†Corresponding author: K. R. Harris-Shultz; Karen.Harris@ars.usda.gov

Funding: This project was funded by the USDA-ARS and the University of Georgia.

*The $\boldsymbol{e}$-Xtra logo stands for "electronic extra" and indicates that one supplementary figure and two supplementary tables are published online.

The author(s) declare no conflict of interest.

This article is in the public domain and not copyrightable. It may be freely reprinted with customary crediting of the source. The American Phytopathological Society, 2019. resistance, created a mapping population, and identified single-nucleotide polymorphism markers using genotyping-by-sequencing of the segregating population. Use of single-marker analysis and composite interval mapping identified a single QTL on chr. 5 that was associated with egg number and egg number per gram of root from the resistant sweet sorghum line PI 144134. This region on chr. 5 and the prior QTL on chr. 3 can be potentially moved from PI 144134 and Honey Drip, respectively, into elite sorghum germplasm via marker-assisted selection for more durable resistance.

Keywords: genetics and resistance, nematology. use of resistant varieties is limited by the number of available resistant genotypes, and resistance, especially monogenic resistance, can be overcome by the nematodes with time (Favery et al. 2016).

Resistance to Meloidogyne spp. has been found in many plant species and is controlled by mostly a small number of genes. In cowpea (Vigna unguiculate L. Walp.), resistance to Meloidogyne incognita and $M$. javanica isolates in lines IT84S-2049, IT93K503-1, and CB27 was conferred by one quantitative trait locus (QTL) with a major effect (Huynh et al. 2016). Similarly, resistance to M. incognita in pearl millet (Pennisetum glaucum (L.) R. Br. line Tift454 is conferred by one major QTL (Liu 2012). Resistance to M. incognita in soybean (Glycine max L. Merr.) line PI 567516C was found to be conferred by three QTLs (Jiao et al. 2015) and resistance to $M$. graminicola in rice (Oryza sativa L.) variety Bala is conferred by four QTLs (Shrestha et al. 2007).

Sorghum, including sweet sorghum, is often not significantly damaged by RKN but some sorghum genotypes have been shown to support greater population densities of RKN (Davis et al. 2015; McSorley and Gallaher 1993). These higher populations act as future inoculum, increasing the risk of damage to subsequent susceptible crops. A recent study examining 29 sorghum hybrids for RKN resistance found that 28 of the sorghum hybrids were susceptible and, thus, the potential for high densities of RKN accumulating in the soil exists (Xavier-Mis et al. 2017). Because farmers often utilize crop rotation and may plant cotton, corn (Zea mays L.), soybean, or other RKN-susceptible crops after sorghum (Xavier-Mis et al. 2017), it is important to understand the location and the number of genes involved in RKN resistance in sorghum. This information is valuable in creating new sorghum hybrids with RKN resistance using marker-assisted selection.

RKN resistance in sorghum has been examined previously using the resistant sweet sorghum cultivar Honey Drip (PI 641821) (Harris-Shultz et al. 2015a). A major QTL on chromosome (chr.) 3 was associated with a reduction in total eggs (57\% phenotypic 
variance) and eggs per gram of root (70\% of the phenotypic variance). The identification of multiple sources of resistance in sorghum, followed by the pyramiding of these genes into elite germplasm using marker-assisted selection, should confer more durable resistance to RKN. In this study, we sought to identify QTLs associated with RKN resistance that contain resistance genes different than Honey Drip.

\section{MATERIALS AND METHODS}

Identification of lines potentially containing a new RKN resistance gene. To identify sorghum lines that potentially have a resistance gene different than Honey Drip, Colman (PI 641810), Leoti-Peltier (PI 642999), Honey Drip (PI 641821), MN 395 (PI 144134), Dale (PI 651495) (Broadhead and Coleman 1973), Top 76-6 (also known as Topper; PI 583832) (Day et al. 1995), M 81E (PI 653411) (Broadhead and Zummo 1983), Entry 22 (HarrisShultz et al. 2015b), Collier (PI 641862), and GT-IR7 (PI 602445) (Widstrom 1998) were genotyped in the sorghum chr. 3 region that was previously found to be associated with reduced egg number and egg number per gram of root (Harris-Shultz et al. 2015a). The sorghum simple sequence repeat (SSR) markers RKNP135, RKNP194, RKNP259, RKNP342, RKNP402, RKNP465, and RKNP529 (Punnuri et al. 2017) (Supplementary Table S1) were amplified in these lines using the previously described reaction and thermocycler conditions (Harris-Shultz et al. 2015a). Polymerase chain reaction (PCR) product $(2 \mu \mathrm{l})$ was combined with $5 \mu$ l of Blue Stop (LI-COR Biosciences, Lincoln, NE, U.S.A.) and $0.35 \mu$ lof this mixture was loaded on a $6.5 \%$ acrylamide gel using a LI-COR Biosciences 4300 DNA Analyzer. Gel images were scored visually. The marker data were imported into NTSYSpc (Rohlf 2008). Genetic similarity between each pair of accessions was calculated using the SIMQUAL module using the DICE coefficient of similarity (Nei and Li 1979). A dendrogram was generated from the similarity matrix by using the unweighted pair-group method with arithmetic mean procedure in the SAHN module of NTSYSpc. Bootstrap resampling was performed using the software program
FreeTree (Hampl et al. 2001) with 1,000 bootstrap repetitions; bootstrap values $>50 \%$ were placed on the resulting dendrogram.

Development of an $F_{2}$ population segregating for $R K N$ resistance. $A n F_{2}$ population (PI $144134 \times$ Collier) was created by hand emasculating florets of PI 144134 and transferring pollen from Collier the following day, for 3 days, to produce potential $F_{1}$ plants. Because sorghum has a high rate of self-pollination and errors can occur during anther removal, plants were confirmed as being a product of the cross by genotyping using the polymorphic SSR markers RKNP194, RKNP259, RKNP342, and RKNP529 (HarrisShultz et al. 2015a; Punnuri et al. 2017), as previously described (Harris-Shultz et al. 2015a). Plants that were identified as true crosses were then self-pollinated, and the resulting $F_{2}$ seed from a single head was planted for subsequent phenotyping and genotyping.

Phenotyping $F_{2}$ plants for $R K N$ egg number, root weight, and Brix. The PI $144134 \times$ Collier $_{2}$ population was phenotyped for RKN response by growing 15 plants of PI 144134, 34 plants of Collier, $198 \mathrm{~F}_{2}$ plants, and 2 plants of the sorghum cultivar ES 5200 (Blade Energy Crops, Ceres, Inc., Thousand Oaks, CA, U.S.A.), a known susceptible hybrid used for forage, in a temperature-controlled greenhouse in steam-pasteurized soil (Tifton loamy sand) in 15-cm-diameter pots with 1 plant/pot. Due to a low number of $F_{1}$ plants being obtained, $F_{1}$ seed was remade and the $\mathrm{F}_{1}$ plants were phenotyped in a second experiment consisting of 14 plants of Collier, 13 plants of PI 144134, and 11 plants of the PI $144134 \times$ Collier $F_{1}$. Plants that had root weights of $<10 \mathrm{~g}$ were excluded from analysis to eliminate plants that had too little root tissue to allow normal amounts of RKN reproduction.

Twenty-eight days after planting, each pot was infested with 8,000 eggs of $M$. incognita race 3 when most plants were still in the vegetative growth stage 1 . Inoculum was collected from eggplant (Solanum melongena L.) roots by agitating roots in $0.5 \%$ sodium hypochlorite solution for $2 \mathrm{~min}$ (Hussey and Barker 1973) $1 \mathrm{~h}$ or less before inoculation. Inoculum was distributed into two holes (approximately $2.5 \mathrm{~cm}$ deep) and covered with soil, and pots were then watered immediately.

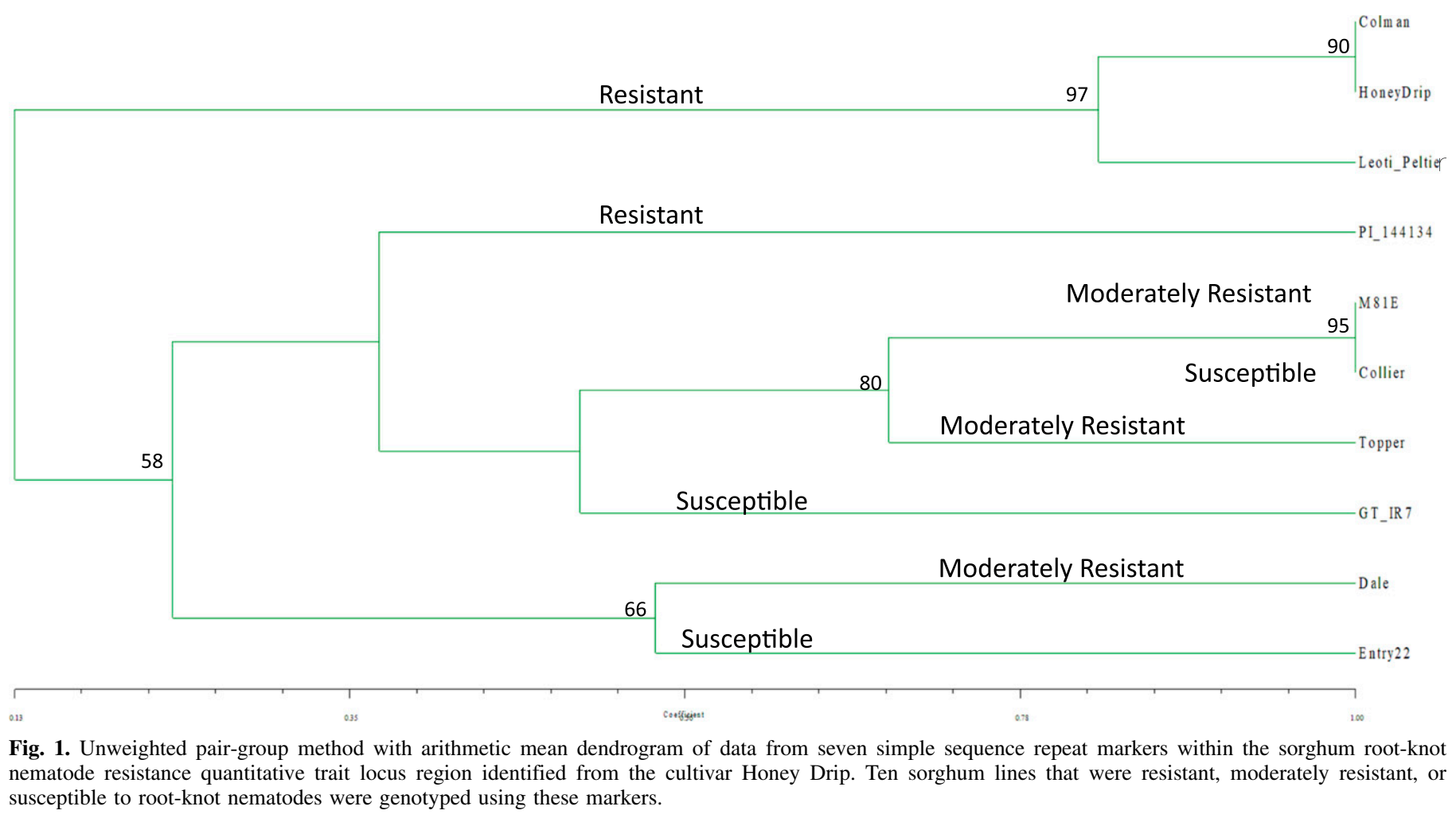


At harvest, 8 weeks after inoculation, when most plants were at anthesis, the stem of each plant was cut at the soil line and leaf tissue was removed for DNA extraction and placed in the $-80^{\circ} \mathrm{C}$ freezer. To determine Brix content, the stems were folded in half and crushed using a home-built billet crusher. The crusher consists of a piece of steel channel mounted on a stand at an angle of approximately $45^{\circ}$. A narrower piece of square steel tubing is connected to the lower end of the channel by a hinge. The billet is placed between the tubing and channel, and pressure is applied manually to extract the juice, which runs down the channel for collection. The degrees Brix was measured from the extracted juice using a digital refractometer (Refracto 30GS; Mettler-Toledo, Schwerzenbach, Switzerland). One degree Brix is equivalent to $1 \mathrm{~g}$ of sucrose in $100 \mathrm{~g}$ of solution.

After the stems were removed, nematode eggs were extracted from all roots in a pot. Roots were gently washed free of soil, cut into approximately $5-\mathrm{cm}$ pieces, and agitated in a $1 \%$ sodium hypochlorite solution in a 1-liter flask for $4 \mathrm{~min}$. Eggs were collected, rinsed with tap water on nested 150 - over 25 - $\mu$ m-pore sieves, and counted under a microscope.

DNA extraction and single-nucleotide polymorphism genotyping. DNA was extracted from each parent and from the $198 \mathrm{~F}_{2}$ plants using the GenJET Plant Genomic DNA Purification Kit (Thermo Fisher Scientific, Waltham, MA, U.S.A.). The parents of the population and $187 \mathrm{~F}_{2}$ progeny were selected for genotypingby-sequencing (GBS) based on having data for root weight, egg counts, and Brix. Tunable GBS (Ott et al. 2017), which has a higher genome reduction level than conventional GBS, was performed by Data2Bio (Ames, IA, U.S.A.) using five runs on an Ion Proton Instrument (Thermo Fisher Scientific) generating an average of 3 million reads per sample. Bases with Phred quality scores of $<15$ of 40 were trimmed. The Sorghum bicolor genome was downloaded from Joint Genome Institute Phytozome v12 website (Goodstein et al. 2012) and was used as the reference genome. Trimmed reads from each sample were aligned to the sorghum reference genome using the Genomic Short-read Nucleotide Alignment Program (Wu and Nacu 2010).
Any nucleotide site that was polymorphic in at least one sample as compared with the reference genome sequence was considered a single-nucleotide polymorphism (SNP). SNPs were retained if the most common allele for a homozygous SNP or the sum of the reads of the two most common alleles for a heterozygous SNP accounted for at least $80 \%$ of all the aligned reads covering that nucleotide position, if at least five unique reads supported the most common allele (or the two most common alleles for heterozygotes), and if each polymorphic base had a Phred base quality value $\geq 20$. Polymorphisms in the first and last $3 \mathrm{bp}$ of each read were ignored. SNPs were further filtered using a minimum call rate $\geq 50 \%$, an allele number of 2 , a minor allele frequency of $\geq 0.35$, and a heterozygosity range of 35 to $65 \%$. SNP genotype calls were provided by Data2Bio.

Correlations and QTL analysis. For egg number, egg number per gram of root, and Brix, data were normalized by using a $\log _{10}(x+1)$ transformation. The Pearson's correlation coefficient between each of the four traits measured was calculated in Excel 2010 (Microsoft Corp, Redmond, WA, U.S.A.). The strength of the correlation coefficients was determined by using the Dancey and Reidy (2004) categorization.

For single-marker analysis (SMA), the raw Data2Bio genotypes were filtered to remove sites with $>55 \%$ heterozygosity across individuals, because preliminary inspection of the data indicated that these were likely false SNPs due to misalignment of paralogs.

TABLE 1. Pearson's correlation coefficients between root weight (Root Wt), egg number (LogEggs), eggs per gram of root (LogEggRoot), and Brix (LogBRIX) measured on 187 PI $144134 \times$ Collier $F_{2}$ plants $^{\mathrm{a}}$

\begin{tabular}{lllcc}
\hline Trait & Root Wt & LogEggs & LogEggRoot & LogBRIX \\
\hline Root Wt & 1 & $\ldots$ & $\ldots$ & $\ldots$ \\
LogEggs & $0.208^{* *}$ & 1 & $\ldots$ & $\ldots$ \\
LogEggRoot & $0.212^{* *}$ & $0.978^{* *}$ & 1 & $\ldots$ \\
LogBRIX & $0.548^{* *}$ & 0.066 & 0.104 & 1 \\
\hline
\end{tabular}

a Asterisks (**) indicate $P<0.01$.
A

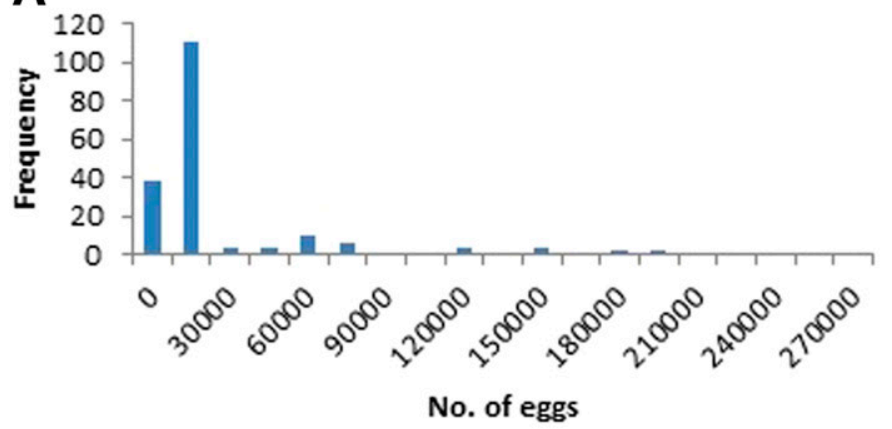

C

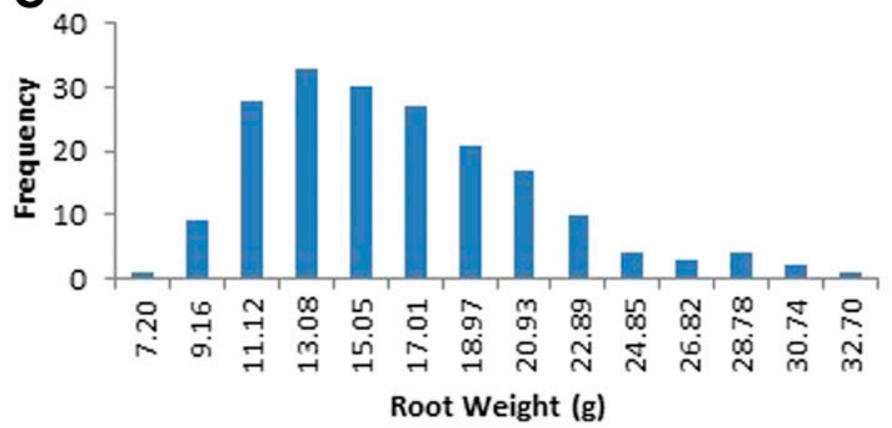

B

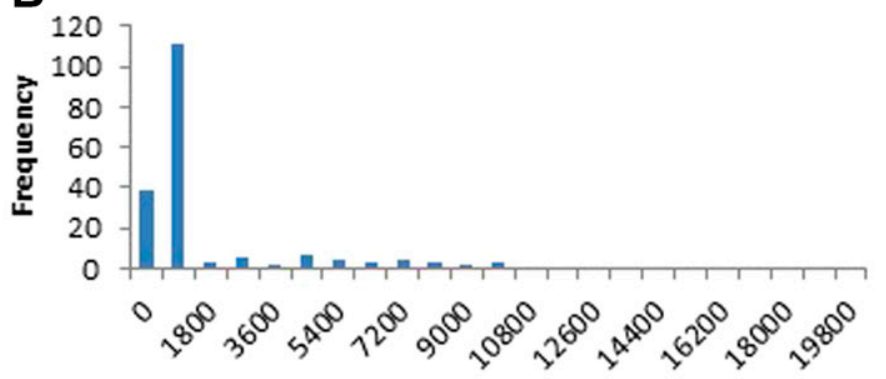

Eggs per gram of root

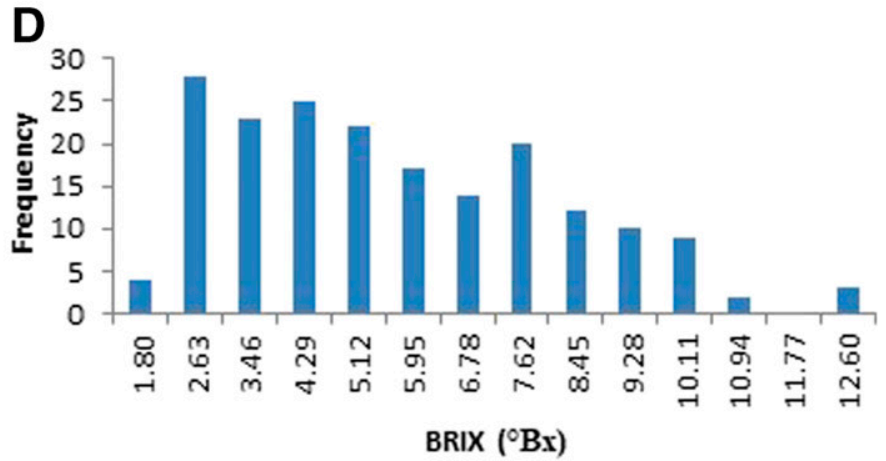

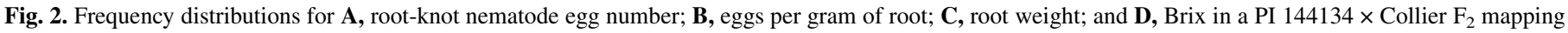
population. 
Genotypes were then imputed with FSFhap (Swarts et al. 2014), except for chr. 5 and 8, which the algorithm was unable to complete (likely due to misplaced markers; data not shown). Redundant markers were then removed with $\mathrm{R}$ (R Core Team 2018). To test whether transformation of the phenotype data would improve mapping power, we estimated the heritability of raw and logtransformed values for all four phenotypes, along with egg number and egg number per gram of root when divided into either two (resistant and susceptible) or three (resistant, intermediate, and susceptible) groups. Note that the log transformation was not $\log (x+1)$; thus, individuals with a count of 0 were set to missing; this was done intentionally because of the extreme skew the 0-count individuals introduced to the distribution, and because they would still be captured by the two- and three-category divisions of the phenotypes. Narrow-sense heritability was estimated using a mixed linear model in TASSEL (Bradbury et al. 2007) to get genetic variance components; this identified the raw root weight, raw Brix, log-transformed egg number, and log-transformed egg number per gram of root as the most robust version of each trait (data not shown). Finally, SMA was performed in TASSEL using a general linear model with 10,000 random permutations of the data to determine empirical $P$ values. The entire SMA workflow is available at https://github.com/wallacelab/2018_sorghum_nematodes.

\section{RESULTS}

Identification of PI 144134 as potentially containing a new RKN resistance gene. In a previous study (Harris-Shultz et al. 2015a), a major QTL on chr. 3 was associated with a reduction in total eggs and eggs per gram of root in the sweet sorghum cultivar Honey Drip. To confer more durable RKN resistance via pyramiding of resistance genes in sorghum lines, additional sorghum lines with RKN resistance were examined with SSR markers located in the Honey Drip QTL region to potentially find alternative resistance genes. Sweet sorghum lines Colman, LeotiPeltier, Honey Drip, and PI 144134 had been previously found to be resistant to RKN (Davis and Anderson 2012). Dale, Top 76-6 (Topper), and M 81E had been found to be moderately resistant,
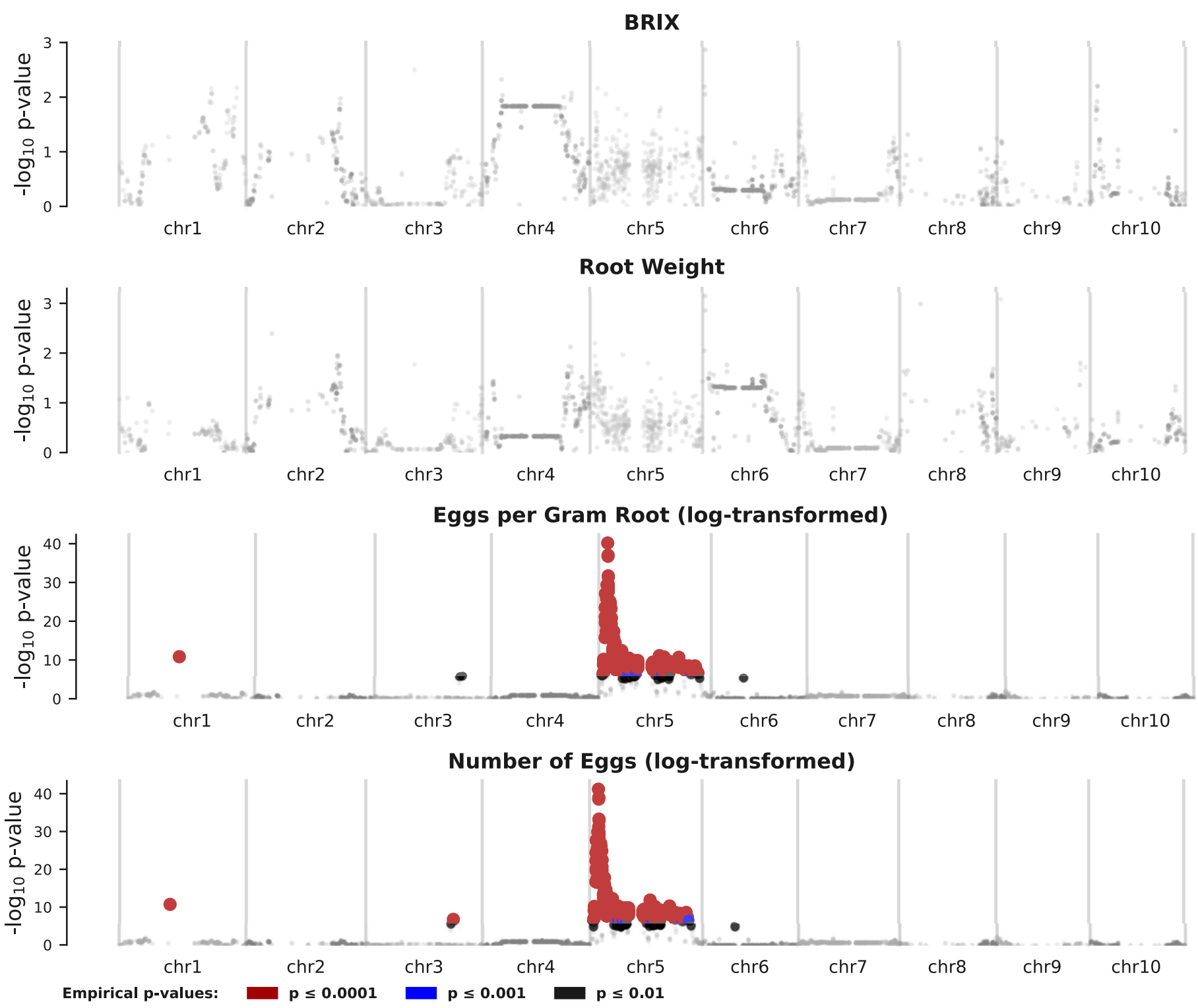

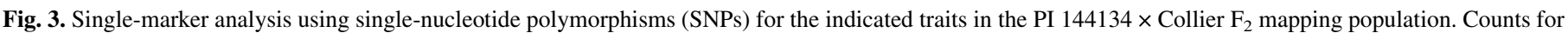

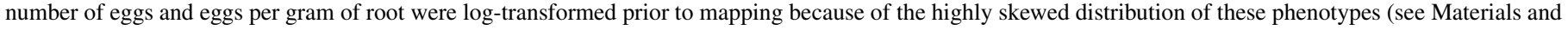

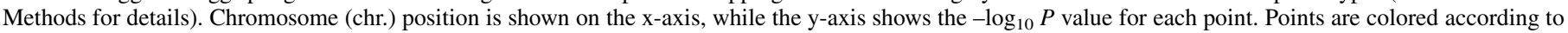

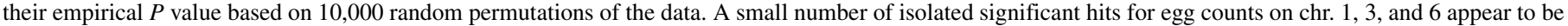
misplaced markers, because including the peak SNP on chr. 5 as a covariate makes these points nonsignificant (data not shown). 
whereas Entry 22, Collier, and GT-IR7 had been found to be susceptible to RKN (Davis and Anderson 2012). Seven SSR markers located in the QTL region associated with reduced egg number and egg number per gram of root were used to genotype the 10 lines. Twenty-eight fragments were generated and resistant lines Colman, Leoti-Peltier, and Honey Drip had similar haplotypes (83 to $100 \%$ genetic similarity) for this region (Fig. 1). Resistant line PI 144134 grouped with lines that were moderately resistant and susceptible and, thus, PI 144134 may have an alternative source of resistance. This line was selected for crossing with susceptible line Collier to create an $\mathrm{F}_{2}$ mapping population.

Phenotypic summary of the PI $144134 \times$ Collier $F_{2}$ population. Total eggs. Total eggs for the resistant parent PI 144134 ranged from 0 to 2,400 eggs whereas the susceptible parent Collier ranged from 18,000 to 295,800 eggs. The $F_{2}$ plants ranged from 0 to 243,600 eggs and the frequency distribution for total eggs is shown (Fig. 2A). The total egg data for the $F_{2}$ plants displays a nonnormal distribution ( individuals skewed toward the resistant parent. Using a cutoff of $\leq 12,000$ eggs for resistant and $\geq 21,000$ eggs for susceptibility, 150 $\mathrm{F}_{2}$ plants were resistant and $40 \mathrm{~F}_{2}$ plants were susceptible. A $\chi^{2}$ test was used to test the goodness of fit to a 3:1 ratio, assuming that a single dominant gene restricts total eggs and supports a single dominant gene $\left(\chi^{2}=1.579, \mathrm{df}=1, P=0.2089\right)$. For the $\mathrm{F}_{1}$ test, total eggs for the resistant parent PI 144134 ranged from 0 to 10,800 eggs, the susceptible parent Collier ranged from 22,200 to 247,800 eggs, and the $\mathrm{F}_{1}$ plants ranged from 4,800 to 36,600 eggs.

Eggs per gram of root. Eggs per gram of root ranged from 0 to 229 eggs/g of root for PI 144134 and 1,362 to 19,720 eggs/g of root for Collier. The $\mathrm{F}_{2}$ plants ranged from 0 to 18,119 eggs/g of root. The $\mathrm{F}_{2}$ frequency distribution was nonnormal (skewness $=2.98$, kurtosis $=$ 10.12) and was skewed toward the resistant parent (Fig. 2B). Similar to egg number, a break in the $\mathrm{F}_{2}$ data was seen and $<871 \mathrm{eggs} / \mathrm{g}$ of root was labeled as resistant, whereas $>1,328$ eggs/g of root was labeled as susceptible. Thus, $150 \mathrm{~F}_{2}$ plants were resistant and $40 \mathrm{~F}_{2}$ plants were susceptible. A $\chi^{2}$ test was used to test the goodness of fit to a 3:1 ratio, assuming that a single dominant gene restricts total eggs per gram of root and supports a single dominant gene $\left(\chi^{2}=1.579\right.$, $\mathrm{df}=1, P=0.2089$ ). For the $\mathrm{F}_{1}$ test, eggs per gram of root ranged from 0 to 1,714 eggs/g of root for PI 144134, 1,708 to 11,939 eggs/g of root for Collier, and 293 to 3,327 eggs/g of root for the $F_{1}$ plants.

Root weight. Root weight for PI 144134 and Collier ranged from 8.4 to 23.3 and 4.4 to $21.2 \mathrm{~g}$, respectively. Using a $t$ test, these parental lines were not significantly different $(t=1.12, \mathrm{df}=16, P=$ 0.14 ) for root weight. The $F_{2}$ plants ranged from 7.2 to $32.7 \mathrm{~g}$ of root weight and the $\mathrm{F}_{2}$ frequency distribution was normally distributed $($ skewness $=0.835$, kurtosis $=0.668)($ Fig. $2 \mathrm{C})$. For the $F_{1}$ test, root weight for PI 144134 and Collier ranged from 10.0 to 16.4 and 12.3 to $42.6 \mathrm{~g}$, respectively. Root weight for the $\mathrm{F}_{1}$ plants ranged from 11.0 to $20.3 \mathrm{~g}$.
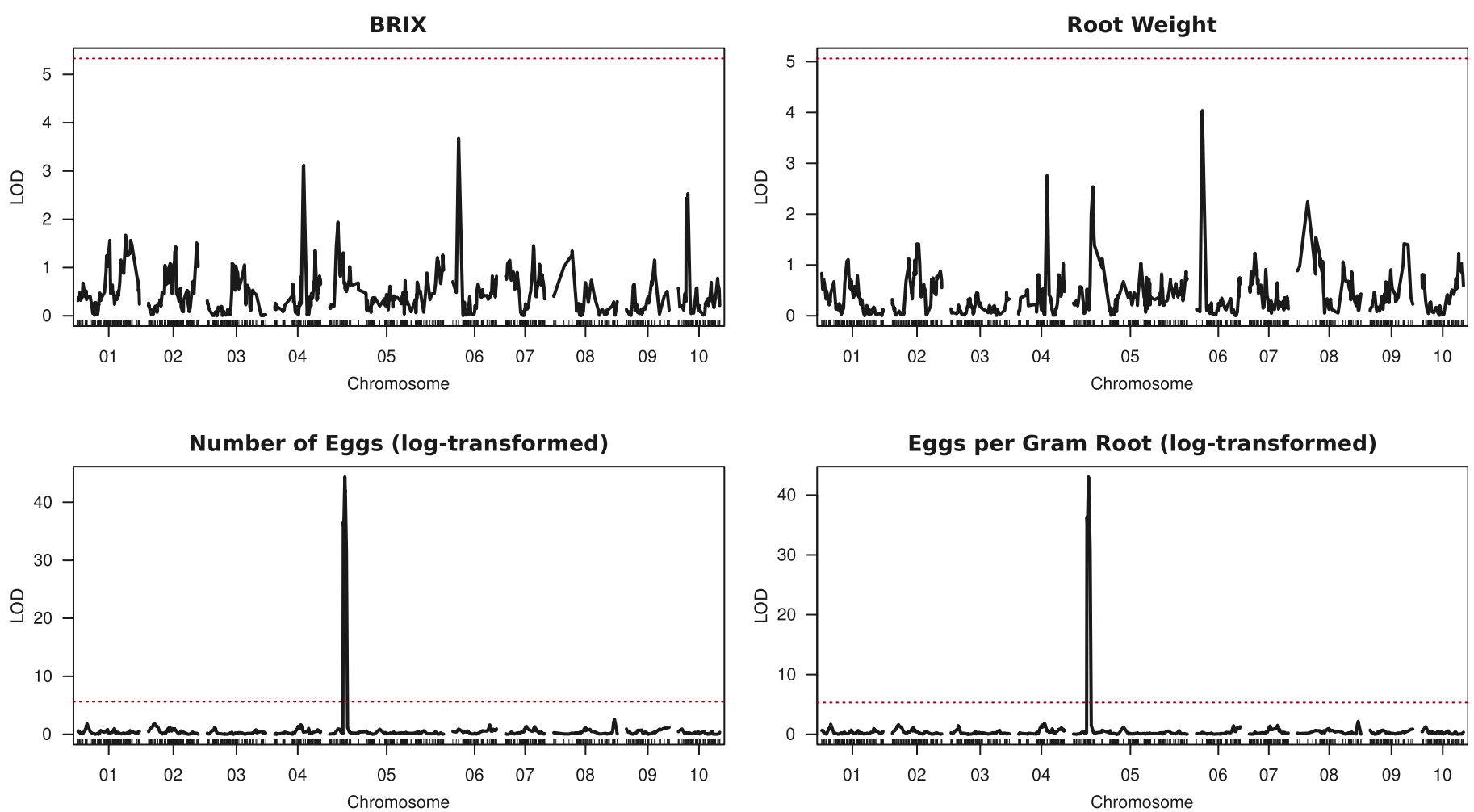

Fig. 4. Composite interval mapping was performed for all traits in R/qtl (Broman et al. 2003). The dotted line represents the 95\% significance threshold determined by 1,000 random permutations of the data. Brix and root weight show no significant hits, while number of eggs and eggs per gram of root both show a single peak on Chromosome 5.

TABLE 2. Identification of quantitative trait loci using composite interval mapping in the PI $144134 \times$ Collier $\mathrm{F}_{2}$ population $^{\mathrm{a}}$

\begin{tabular}{lccccccc}
\hline Trait & LG/cM & SNP & Log of odds & Additive $^{\text {b }}$ & Dominance $^{\text {b }}$ & $R^{2}$ & Chr./bp \\
\hline EggRoot $(\log )$ & $5 / 45.97$ & $\mathrm{~s} 1221$ & 42.92 & $-3.68(39.6 \times)$ & $-1.44(4.2 \times)$ & 0.72 & $5 / 5,608,057$ \\
EggNo. $(\log )$ & $5 / 45.97$ & $\mathrm{~s} 1221$ & 44.37 & $-3.77(43.4 \times)$ & $-1.36(3.9 \times)$ & 0.73 & $5 / 5,608,057$ \\
\hline
\end{tabular}

a Abbreviations: $\mathrm{LG}=$ linkage group, $\mathrm{cM}=$ centimorgans, $\mathrm{SNP}=$ single-nucleotide polymorphism, and Chr. $=$ chromosome.

$\mathrm{b}$ The sign of the estimated additive and dominance effects are associated with the allele from the female (resistant) parent. Values are on a natural log scale, with the associated fold-change shown in parentheses. 
Brix. The Brix values between PI 144134 and Collier were significantly different using a $t$ test $(t=1.97, \mathrm{df}=16, P=0.03)$. The Brix values for PI 144134 ranged from 1.5 to $8.5^{\circ} \mathrm{Bx}$, Collier ranged from 2.7 to $11.6{ }^{\circ} \mathrm{Bx}$, and the $\mathrm{F}_{2}$ progeny ranged from 1.8 to $12.6^{\circ} \mathrm{Bx}$. The $\mathrm{F}_{2}$ frequency distribution is multimodal with peaks seen at $2.63,4.29$, and $7.62{ }^{\circ} \mathrm{Bx}$ and has a light tailed distribution (skewness $=0.584$, kurtosis $=-0.387$ ) (Fig. 2D). Brix values were not taken on the $\mathrm{F}_{1}$ plants.

Correlation among phenotypic traits. A moderate correlation was seen between root weight and Brix (Table 1) $(r=0.55)$. Similarly, a strong correlation was seen between egg number and eggs per gram of root (Table 1$)(r=0.98)$.

Marker by trait association analysis. Single-marker association was used to identify marker-trait associations between 911 nonredundant SNP markers and four traits from $187 \mathrm{~F}_{2}$ progeny. Of all the traits examined, only egg number and egg number per gram of root had a significant marker-trait association, with peak association at a single marker, s1221, on chr. 5 at 5,608,057 bp (Fig. $3)$. Presence of the PI 144134 allele in the homozygous or heterozygous condition for this SNP resulted in $\mathrm{F}_{2}$ progeny having between 0 to 12,000 eggs and 0 to $586 \mathrm{eggs} / \mathrm{g}$ of root. Presence of the Collier allele in the homozygous condition for SNP s1221 resulted in the $\mathrm{F}_{2}$ progeny having egg numbers that ranged between 12,000 to 243,600 eggs and 870 to $17,177 \mathrm{eggs} / \mathrm{g}$ of root. Three progeny (F2_71, F2_165, and F2_216) are outliers whose egg count is in the range of the opposite genotype; these may be genotyping errors and, thus, are excluded from the above ranges.

Composite interval mapping (CIM) was performed in R/qtl (Broman et al. 2003) after calculating genetic map distances and removing misplaced markers that created large gaps in the map due to errant segregation. CIM also confirmed that a single QTL with its peak log of odds at s1221 (Fig. 4) is associated with the number of RKN eggs and number of eggs per gram of root. No QTLs were detected for Brix or root weight (Fig. 4). The QTL effect for both the number of eggs and eggs per gram of root was high $\left(R^{2}=72\right.$ to $73 \%)$ and both overlapping QTLs showed partial dominance $(\mathrm{D} / \mathrm{A}=$ 0.36 to 0.39 ) (Stuber et al. 1987) (Table 2).

\section{DISCUSSION}

The moderate correlation between root weight and Brix (Table 1) for the PI $144134 \times$ Collier $F_{2}$ population had been previously seen in the Honey Drip $\times$ Collier RKN $F_{2}$ mapping population (HarrisShultz et al. 2015a). Although correlations do not imply causation, one could speculate that, for sweet sorghum plants, healthier plants with larger root weights may have a better ability to accumulate sugars.

A frequency distribution for root weight and Brix (Fig. 2) indicated that these traits are controlled by a large number of genes. In contrast, the number of eggs or the number of eggs per gram of root is controlled by a small number of genes (Fig. 2). Genotyping in the Honey Drip QTL region, QTL-Sb.RKN.3.1, of 10 inbred lines with various responses to RKN revealed that PI 144134 may have a novel resistance gene. Use of SMA and CIM identified a single QTL on chr. 5 that is associated with the number of RKN eggs or the number of eggs per gram of root (Figs. 3 and 4). Thus, we were successful in identifying a new resistance locus associated with egg number and egg number per gram of root from PI 144134 which is different than the major gene found from Honey Drip on sorghum chr. 3. This new QTL will be here named QTL-Sb.RKN.5.1.

Plant resistance proteins recognize the corresponding pathogen avirulence proteins through direct interaction or indirectly through detection of changes in the host protein targets (Dodds et al. 2006). This recognition event between resistance and avirulence proteins causes host defense responses, mainly manifested as a hypersensitive response, which is the rapid death of the invaded cell and, in some cases, some of the surrounding cells (Dodds et al. 2006). Resistance gene analogs can be classified as nucleotide-binding leucine-rich repeat (NBS-LRR), transmembrane LRR proteins, and other modes of resistance such as pentatricopeptide repeats and peroxidases (Sekhwal et al. 2015). Many of the genes that have been found to be involved with nematode resistance in plants include those that encode members of the NBS-LRR family of proteins (Ernst et al. 2002; Lagudah et al. 1997; Milligan et al. 1998). Similarly, the Hs1pro-1 gene from sugar beet (Beta vulgaris L.) which confers resistance to the beet cyst nematode (Heterodera schachtii) has imperfect LRRs and a putative transmembrane domain (Cai et al. 1997). In soybean, the loci Rhgl and Rhg4, which confer resistance to $H$. glycines type 0 , encode proteins with extracellular LRRs, a transmembrane domain, and a cytosolic serine-threonine kinase domain. Examination of the chr. 5 QTL area from 5,170,367 to 5,790,187 bp (Supplementary Table S2) revealed one gene that contains an N-terminal LRR and a serine-threonine protein kinase domain, Sobic.005G055900, near the peak QTL region starting at 5,657,820 bp. There are also 11 additional genes encoding an LRR domain nearby but further away from the peak SNP. Further examination using root gene expression differences between the parental lines or further fine-mapping may help narrow the number of candidate genes.

\section{ACKNOWLEDGMENTS}

We thank N. Flader, D. Clements, D. F, Cheek, and S. Drawdy for technical expertise; and P. Wadl and P. Wechter for review of this manuscript.

\section{LITERATURE CITED}

Bradbury, P. J., Zhang, Z., Kroon, D. E., Casstevens, T. M., Ramdoss, Y., and Buckler, E. S. 2007. TASSEL: Software for association mapping of complex traits in diverse samples. Bioinformatics 23:2633-2635.

Broadhead, D. M., and Coleman, O. H. 1973. Registration of Dale sweet sorghum. Crop Sci. 13:776.

Broadhead, D. M., and Zummo, N. 1983. M 81E sweet sorghum. Crop Sci. 23: 1013.

Broman, K. W., Wu, H., Sen, S., and Churchill, G. A. 2003. R/qtl: QTL mapping in experimental crosses. Bioinformatics 19:889-890.

Cai, D., Kleine, M., Kifle, S., Harloff, H. J., and Sandal, N. N. 1997. Positional cloning of a gene for nematode resistance in sugar beet. Science 275: 832-834.

Choi, I., Subramanian, P., Shim, D., Oh, B.-J., and Hahn, B.-S. 2017. RNA-Seq of plant-parasitic nematode Meloidogyne incognita at various stages of its development. Front. Genet. 8:190.

Crow, W. T. 2005. Biologically derived alternatives to Namacur. Golf Course Manage. 73:147-150.

Dancey, C. P., and Reidy, J. 2004. Statistics Without Maths for Psychology: Using SPSS for Windows, 3rd Ed. Pearson, Prentice Hall, New York, NY, U.S.A.

Danchin, E. G. J., Arguel, M.-J., Campan-Fournier, A., Perfus-Barbeoch, L., Magliano, M., Rosso, M.-N., Da Rocha, M., Da Silva, C., Nottet, N., Labadie, K., Guy, J., Artiguenave, F., and Abad, P. 2013. Identification of novel target genes for safer and more specific control of root-knot nematodes from a PanGenome mining. PLoS Pathog. 9:e1003745.

Davis, R. F., and Anderson, W. F. 2012. Identification of widely varying levels of resistance to Meloidogyne incognita in sweet sorghum. J. Nematol. 44: 475.

Davis, R. F., Knoll, J. E., Anderson, W. F., and Harris-Shultz, K. R. 2015. Tolerance of sweet sorghum to Meloidogyne incognita and crop effect on nematode population density. (Abstr.) J. Nematol. 47:232.

Day, J. L., Duncan, R. R., Raymer, P. L., Thompson, D. S., and Zummo, N. 1995. Registration of 'Top 76-6' sweet sorghum. Crop Sci. 35:1211-1213.

Dodds, P. N., Lawrence, G. J., Catanzariti, A.-M., Teh, T., Wang, C.-I., Ayliffe, M. A., Kobe, B., and Ellis, J. G. 2006. Direct protein interaction underlies gene-for-gene specificity and coevolution of the flax resistance genes and flax rust avirulence genes. Proc. Natl. Acad. Sci. U.S.A. 103:8888-8893.

Donkers-Venne, D. T. H. M., Fargette, M., and Zijlstra, C. 2000. Identification of Meloidogyne incognita, M. javanica, and $M$. arenaria using sequence characterized amplified region (SCAR) based PCR assays. Nematology 2: 847-853.

Ernst, K., Kumar, A., Krisleit, D., Kloos, D. U., Phillips, M. S., and Ganal, M. W. 2002. Broad-spectrum potato cyst nematode-resistance gene (Hero) from tomato is the only member of a large gene family of NBS LRR-genes with an unusual amino acid repeat in the LRR region. Plant J. 31:127-136. 
Favery, B., Quentin, M., Jaubert-Possamai, S., and Abad, P. 2016. Gallforming root-knot nematodes hijack key plant cellular functions to induce multinucleate and hypertrophied feeding cells. J. Insect Physiol. 84:60-69.

Goodstein, D. M., Shu, S., Howson, R., Neupane, R., Hayes, R. D., and Fazo, J. 2012. Phytozome: A comparative platform for green plant genomics. Nucleic Acids Res.: D1178-D1186.

Hampl, V., Pavlicek, A., and Flegr, J. 2001. Construction and bootstrap analysis of DNA fingerprinting-based phylogenetic trees with a freeware program FreeTree: Application to trichomonad parasites. Int. J. Syst. Evol. Microbiol. 51:731-735.

Harris-Shultz, K., Ni, X., Wang, H., Knoll, J. E., and Anderson, W. F. 2015b. Use of benzimidazole agar plates to assess fall armyworm (Lepidoptera: Noctuidae) feeding on excised maize and sorghum leaves. Fla. Entomol. 98: 394-397.

Harris-Shultz, K. R., Davis, R. F., Knoll, J. E., Anderson, W., and Wang, H. 2015a. Inheritance and identification of a major quantitative trait locus (QTL) that confers resistance to Meloidogyne incognita and a novel QTL for plant height in sweet sorghum. Phytopathology 105:1522-1528.

Hussey, R. S., and Barker, K. R. 1973. A comparison of methods of collecting inocula of Meloidogyne spp., including a new technique. Plant Dis. Rep. 57: 1025-1028.

Huynh, B.-L., Matthews, W. C., Ehlers, J. D., Lucas, M. R., Santos, J. R. P., Ndeve, A., Close, T. J., and Roberts, P. A. 2016. A major QTL corresponding to the $R k$ locus for resistance to root-knot nematodes in cowpea (Vigna unguiculata L. Walp.). Theor. Appl. Genet. 129:87-95.

Jiao, Y., Vuong, T. D., Liu, Y., Li, Z., Noe, J., Robbins, R. T., Joshi, T., Xu, D., Shannon, J. G., and Nguyen, H. T. 2015. Identification of quantitative trait loci underlying resistance to southern root-knot and reniform nematodes in soybean accession PI 567516C. Mol. Breed. 35:131.

Lagudah, E. S., Moullet, O., and Appels, R. 1997. Map-based cloning of a gene sequence encoding a nucleotide-binding domain and a leucine-rich region at the Cre3 nematode resistance locus of wheat. Genome 40: 659-665.

Liu, L. 2012. Genetic mapping and quantitative trait locus (QTL) analysis of root-knot nematode resistance in pearl millet. $\mathrm{Ph} . \mathrm{D}$. dissertation, University of Georgia, Athens, GA, U.S.A.

McSorley, R., and Gallaher, R. N. 1993. Population densities of root-knot nematodes following corn and sorghum in cropping systems. Pages 26-29 in: South. Conserv. Tillage Conf. Sustain. Agric. P. K. Bollich, ed. Proc. Agric. Exp. Stn. 93-86-7122.
Milligan, S. B., Bodeau, J., Yaghoobi, J., Kaloshian, I., Zabel, P., and Williamson, V. M. 1998. The root knot nematode resistance gene $M i$ from tomato is a member of the leucine zipper, nucleotide binding, leucine-rich repeat family of plant genes. Plant Cell 10:1307-1319.

Nei, M., and Li, W. H. 1979. Mathematical model for studying genetic variation in terms of restriction endonucleases. Proc. Natl. Acad. Sci. U.S.A. 76:5269-5273.

Ott, A., Liu, S., Schnable, J. C., Yeh, C.-T., Wang, C., and Schnable, P. S. 2017. Tunable genotyping-by-sequencing (tGBS®) enables reliable genotyping of heterozygous loci. bioRxiv. doi:10.1101/100461

Punnuri, S., Harris-Shultz, K., Knoll, J., Ni, X., and Wang, H. 2017. The genes $B m 2$ and Blmc that affect epicuticular wax deposition in sorghum are allelic. Crop Sci. 57:1552-1556.

R Core Team. 2018. R: A Language and Environment for Statistical Computing. R Foundation for Statistical Computing, Vienna, Austria. https:// www.R-project.org/

Ramana, K. V., and Eapen, S. J. 1995. Parasitic nematodes and their management in major spices. J. Spices Aromat. Crops 4:1-16.

Rohlf, F. J. 2008. NTSYSpc: Numerical Taxonomy System, ver. 2.20. Exeter Publishing, Ltd, Setauket, NY, U.S.A.

Sekhwal, M. K., Li, P., Lam, I., Wang, X., Cloutier, S., and You, F. M. 2015. Disease resistance gene analogs (RGAs) in plants. Int. J. Mol. Sci. 16: 19248-19290

Shrestha, R., Uzzo, F., Wilson, M. J., and Price, A. H. 2007. Physiological and genetic mapping study of tolerance to root-knot nematode in rice. New Phytol. 176:665-672.

Stuber, C. W., Edwards, M. D., and Wendel, J. F. 1987. Molecular markerfacilitated investigations of quantitative trait loci in maize. II. Factors influencing yield and its component traits. Crop Sci. 27:639-648.

Swarts, K., Li, H., Navarro, J. A. R., An, D., Romay, M. C., Hearne, S., Acharya, C., Glaubitz, J. C., Mitchell, S., Elshire, R. J., Buckler, E. S., and Bradbury, P. J. 2014. Novel methods to optimize genotypic imputation for low-coverage, next-generation sequence data in crop plants. Plant Genome 7.

Widstrom, N. W. 1998. Registration of sorghum germplasm lines GT-IR6, GT-IR7, and GT-IR8. Crop Sci. 38:1410-1411.

Wu, T. D., and Nacu, S. 2010. Fast and SNP-tolerant detection of complex variants and splicing in short reads. Bioinformatics 26:873-881.

Xavier-Mis, D. M., Overstreet, C., McGawley, E. C., and Doyle, V. P. 2017. Susceptibility of grain sorghum cultivars to Meloidogyne incognita in Louisiana, U.S.A. Nematropica 47:86-98. 